\title{
The Calcitonin Receptor Plays a Major Role in Glucose Regulation as a Function of Dual Amylin and Calcitonin Receptor Agonist Therapy
}

\author{
(1) Anna Thorsø Larsen, Nina Sonne, Kim Vietz Andreassen, Morten Asser Karsdal, \\ and Kim Henriksen
}

Nordic Bioscience Biomarkers and Research, Department of Endocrinology, Herlev, Denmark

Received October 22, 2019; accepted April 20, 2020

\begin{abstract}
Amylin treatment improves body weight and glucose control, although it is limited by a short action and need for high doses. Dual amylin and calcitonin receptor agonists (DACRAs) are dual amylin and calcitonin receptor agonists with beneficial effects beyond those of amylin. However, to what extent the additional benefits reside in their higher potency or their targeting of the calcitonin receptor remains unclear. Here we deconstruct the receptors involved in the effects of a DACRA, KBP-088, by comparing it to rat amylin ( $\mathrm{rAMY}$ ), rat calcitonin ( $\mathrm{rCT}$ ), and their combination in obese high-fat diet (HFD) and diabetic Zucker diabetic fatty (ZDF) rats. HFD-fed Sprague-Dawley rats and ZDF rats were treated for 4 weeks with KBP-088 (5 $\mu \mathrm{g} / \mathrm{kg}$ per day), rAMY $(300 \mu \mathrm{g} / \mathrm{kg}$ per day), rCT (300 $\mu \mathrm{g} / \mathrm{kg}$ per day), and the combination of rAMY and $\mathrm{rCT}(300+300 \mu \mathrm{g} / \mathrm{kg}$ per day) using infusion pumps. Body weight, food intake, fasting glycemia, glycated hemoglobin type A1c levels, and glucose tolerance were assessed. In obese HFD-fed rats, KBP-088, rAMY, and the combination of $\mathrm{rAMY}$ and $\mathrm{rCT}$ significantly reduced body weight and improved glucose tolerance, whereas $\mathrm{rCT}$ alone had no
\end{abstract}

effect. In diabetic ZDF rats, rCT was efficient in lowering fasting glycemia similar to rAMY, whereas dual activation by KBP-088 and the combination of $\mathrm{rAMY}$ and $\mathrm{rCT}$ were superior to activating either receptor alone. In conclusion, calcitonin therapy regulates fasting blood glucose in a diabetic rat model, thereby underscoring the importance of calcitonin receptor activation as well as the known role of amylin receptor agonism in the potent metabolic benefits of this group of peptides.

\section{SIGNIFICANCE STATEMENT}

We deconstruct the receptors activated by dual amylin and calcitonin receptor agonist (DACRA) therapy to elucidate through which receptor the beneficial metabolic effects of the DACRAs are mediated. We show that calcitonin receptor activation is important for blood glucose regulation in diabetes. This is in addition to the known metabolic beneficial role of amylin receptor activation. These data help in understanding the potent metabolic benefits of the DACRAs and underline the potential of DACRAs as treatment for diabetes and obesity.

\section{Introduction}

The amylin analog pramlintide is approved as adjunct therapy to insulin for both type 1 and type 2 diabetes (Weyer et al., 2001; Hollander et al., 2003; Ratner et al., 2004; Riddle et al., 2007; Ryan et al., 2008). Pramlintide works by reducing postprandial blood glucose excursions and appetite, thereby leading to improved glucose control as well as a weight loss (Aronne et al., 2007; Ryan et al., 2008; Smith et al., 2008; Singh-Franco et al., 2011; Traina and Kane, 2011; Herrmann et al., 2014). On the other hand, pramlintide is limited by its short time of action and need for high doses (Dunican et al., 2010; Younk et al., 2011), and therefore peptides with potent amylin receptor agonistic properties are being carefully investigated.

M.A.K. and K.H. own stock in Nordic Bioscience. M.A.K., K.V.A. and K.H. hold patent in KBP-088. All other authors disclose no conflict of interest.

https://doi.org/10.1124/jpet.119.263392.
Dual amylin and calcitonin receptor agonists (DACRAs) are a novel group of peptides in this family, and studies of these have clearly demonstrated that they possess metabolic efficacy beyond that of amylin on classic amylin-related effects, such as weight loss and postprandial glucose control (Andreassen et al., 2014a; Gydesen et al., 2016; Hjuler et al., 2016). Importantly, several DACRA studies using pair-fed groups have shown that DACRA treatment induces body weight loss, delay of gastric emptying, and improved glucose tolerance superior to that explained by a reduced food intake (Andreassen et al., 2014a; Gydesen et al., 2016, 2017b; Hjuler et al., 2016). Furthermore, DACRAs elicit markedly positive effects on fasting hyperglycemia and glycated hemoglobin type A1c (HbA1c) levels in animal models of type 2 diabetes (Andreassen et al., 2014a; Gydesen et al., 2017b; Hjuler et al., 2017), effects not seen with amylin therapy alone. At the molecular level, DACRAs differ from amylin because they activate both the amylin receptor (AMY-R) and the calcitonin receptor (CTR) and do so potently (Andreassen et al., 2014b; Gydesen

ABBREVIATIONS: AMY-R, amylin receptor; CT, calcitonin; CTR, CT receptor; DACRA, dual amylin and calcitonin receptor agonist; HbA1c, glycated hemoglobin type A1c; HFD, high-fat diet; KBP, KeyBiosciencePeptide; OGT, oral glucose tolerance test; RAMP, receptor activity-modifying protein; rAMY, rat amylin; rCT, rat calcitonin; tAUC, total area under the curve; ZDF, Zucker diabetic fatty. 
et al., 2016). Importantly, the CTR and AMY-R share the core 7-transmembrane $\mathrm{G}$ protein-coupled receptor, although the AMY-R is formed by interaction of a CTR with a receptor activity-modifying protein (RAMP). The interaction with a RAMP switches the receptor from a high-affinity CTR to a high-affinity AMY-R (Armour et al., 1999; Christopoulos et al., 1999; Muff et al., 1999) (Fig. 1). Despite the AMY-R being a CTR with a RAMP, the known effects of its corresponding ligands are diverse, with amylin working primarily on several metabolic parameters, whereas calcitonin (CT) is mostly known to inhibit osteoclast-mediated bone resorption and reduce plasma calcium (Findlay and Sexton, 2004; Inzerillo et al., 2004; Tankó et al., 2004; Henriksen et al., 2016).

However, to what extent the superior activity of the DACRAs resides in their potency and to what extent it resides in the dual receptor activation are presently unknown because of the difficulties of separating the AMY-R-mediated effects from the putative CTR-mediated effects. In a recent study, we showed that even when correcting for the different activity profiles the DACRA KBP-088 is superior to amylin therapy in terms of body weight loss and glucose tolerance in high-fat diet-fed rats (Larsen et al., 2019). However, the contribution of the CTR in DACRA therapy has not been studied previously, hence to what extent the CTR is involved in the DACRA-mediated effects, particularly on glucose homeostasis and insulin sensitivity, is unknown. Furthermore, whether a DACRA response can be obtained by combination of the selective ligands, amylin and calcitonin, when delivered by continuous infusion is not known.

In this study, we use infusion pumps to compensate for differences in potency and effect time between the peptide ligands. Through this we deconstruct the receptors involved in the effect of a highly potent DACRA, KBP-088, by comparing it to rat amylin (rAMY), rat calcitonin (rCT), and the combination of rAMY and rCT on long-term efficacy in rats fed high-fat diets and as intervention in Zucker diabetic fatty (ZDF) rats suffering from obesity and hyperglycemia.

\section{DACRA}
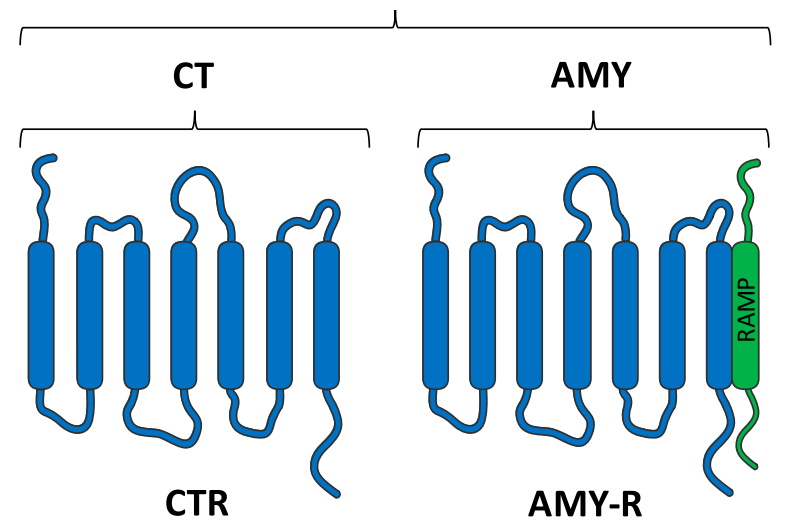

Fig. 1. Schematic overview of the AMY-R and the CTR and their ligands. CTR and AMY-R share the core 7-transmembrane G protein-coupled receptor, although the AMY-R is formed by interaction of a CTR with a RAMP. DACRAs can bind and activate both AMY-R and CTR, whereas AMY and CT are selective for the AMY-R and CTR, respectively. AMY: amylin, CT: calcitonin, DACRA: dual amylin and calcitonin receptor agonist, RAMP: receptor activity-modifying protein.

\section{Materials and Methods}

\section{Peptide Therapy}

Synthetic KBP-088, rat calcitonin (lot JT-71548 high-fat diet (HFD) and JT-76457 (ZDF)), and rat amylin (lot JT-74056 (HFD) and JT76456 (ZDF)) (SynPeptide, Shanghai, China) were dissolved in saline $(\mathrm{NaCl} 0.9 \%)$ for subcutaneous delivery. The amino acid sequence of KBP-088 has previously been published head-to-head with the amino acid sequence of rat amylin (Larsen et al., 2019). The dose chosen for KBP-088 administration was based on previous studies using KBP088 (Gydesen et al., 2016) and other DACRAs (Hjuler et al., 2015, 2016, 2017; Gydesen et al., 2017a). The doses chosen for amylin and calcitonin were based on a previous study testing increasing doses of amylin in a similar setup (Larsen et al., 2019).

\section{Animal Experiments}

All animal procedures were performed in accordance with guidelines from the Animal Welfare Division of the Danish Ministry of Justice under the institutional license issued to Nordic Bioscience (2016-15-0201-00910). Animals were housed pairwise in standard type IV cages (Scanbur A/S, Karlslunde, Denmark) under controlled temperature $\left(21-23^{\circ} \mathrm{C}, 55 \%-65 \%\right.$ relative humidity) and a normal 12 hour light/dark cycle with ad libitum access to food and water. Two studies were performed. In both studies animals received dosing of KBP-088 (5 $\mu \mathrm{g} / \mathrm{kg}$ per day s.c.), rat amylin (300 $\mu \mathrm{g} / \mathrm{kg}$ per day s.c.), rat calcitonin (300 $\mu \mathrm{g} / \mathrm{kg}$ per day s.c.), a combination of rat amylin and rat calcitonin (300 $\mu \mathrm{g} / \mathrm{kg}$ per day s.c.), and vehicle (saline) for 4 weeks. Group size was determined based on previous studies with similar experimental setups (Hjuler et al., 2015, 2016, 2017; Gydesen et al., 2017a). Peptides and vehicle were delivered by continuous subcutaneous infusion through Alzet osmotic pumps (model 2ML4; AgnTho's, Lidingö, Sweden). Under isoflurane anesthesia, animals were surgically equipped with an osmotic pump subcutaneously in the neck region. Initially the skin was locally anesthetized at the site of incision (Marcaine injection) and animals received analgesia (Norodyl injection) 3 days postsurgery.

Animal Study 1) 4-Week Treatment of High-Fat Diet-Fed Rats. Forty male Sprague-Dawley rats (Envigo, Venray, The Netherlands) were obtained at 5 to 6 weeks of age. All rats were fed a $60 \mathrm{kcal}$ $\%$ fat HFD (58Y1; TestDiet, London, UK) from arrival and throughout the study period. After 12 weeks on HFD, rats were randomized into treatment groups according to body weight with an average of $507 \pm$ 22 (S.D.) g ( $n=8$ rats/treatment group). Body weight and food intake were monitored daily for the initial 10 days of the study and then every 3rd day throughout the study period. At study end, an oral glucose tolerance test (OGTT) $(2 \mathrm{~g} / \mathrm{kg}, 4 \mathrm{ml} / \mathrm{kg}$ ) was performed in overnightfasted rats. To assess the effect on gastric emptying, rats received acetaminophen $(40 \mathrm{mg} / \mathrm{kg})$ by oral gavage together with the glucose bolus during OGTT, and the appearance of acetaminophen in plasma was measured 30 minutes postadministration. At study end, rats were euthanized by exsanguination (under isoflurane anesthesia), and this was followed by dissection. Epididymal, perirenal, and subcutaneous inguinal fat depots were surgically removed and weighed.

Animal Study 2) 4-Week Intervention Study in ZDF Rats. Forty male ZDF ( $f a / f a)$ rats (Charles River Laboratories, Lyon, France) were obtained at 5 weeks of age. This model was selected because it is a common rat model in type 2 diabetes research testing new therapies (Pick et al., 1998; Shibata et al., 2000; Topp et al., 2007; King, 2012). All rats were fed Purina Laboratory Diet (5008; LabDiet, St. Louis, MO) from arrival and throughout the study period. Rats were allowed to develop diabetes before they were randomized into treatment groups primarily according to fasting blood glucose levels ( 6 hours) and secondarily according to body weight ( $n=8$ rats/treatment group). At study start, rats weighed $335 \pm 12$ (S.D.) $\mathrm{g}$ and had a fasting blood glucose level at $11.3 \pm 5.7$ (S.D.) mM. Body weight and food intake were monitored daily for the 1st week of the study and then twice per week throughout the study. Fasting blood glucose levels 
( 6 hours) were measured weekly, and HbA1c levels were measured at study end. After 26 days of treatment, an OGTT ( $1 \mathrm{~g} / \mathrm{kg}, 2 \mathrm{ml} / \mathrm{kg})$ was performed in rats fasted for 11 hours. To assess the effect on gastric emptying, rats received acetaminophen $(20 \mathrm{mg} / \mathrm{kg})$ by oral gavage together with the glucose bolus during OGTT, and the appearance of acetaminophen in plasma was measured 30 minutes postadministration. At study end, rats were fasted 6 hours, blood was sampled, and rats were euthanized by exsanguinations under isoflurane anesthesia. Epididymal, perirenal, and subcutaneous inguinal fat depots were surgically removed and weighed, and pancreases were surgically removed and stored for analysis of insulin content.

\section{Glucose Tolerance Test}

OGTTs were performed in overnight-fasted (11 hours) rats. A glucose bolus (Sigma-Aldrich, Copenhagen, Denmark) was administered per os gavage at time 0 . EDTA blood samples were collected from the tail vein before glucose challenge ( 0 minutes) and then after 15,30 , 60 , and 120 minutes post-glucose challenge. Blood glucose was monitored at times $0,15,30,60,120$, and 180 minutes post-glucose challenge.

\section{Biochemical Analysis}

Blood samples were collected in EDTA tubes and centrifuged at $5000 \mathrm{rpm}$ for 10 minutes at $4^{\circ} \mathrm{C}$, and plasma was kept at $-20^{\circ} \mathrm{C}$ until further analysis. Blood glucose was monitored by Accu-Check Avia monitoring system (Roche Diagnostics, Rotkreuz, Switzerland). HbA1c levels were measured by DCA Vantage Analyzer (Siemens, Erlangen, Germany). Plasma levels of insulin (Mercodia Rat Insulin ELISA, RRID: AB_2811229; Mercodia AB, Uppsala, Sweden) and acetaminophen (Neogen Corporation's Acetaminophen ELISA Kit; Neogen Toxicology, KY) were analyzed according to manufacturer's instructions.

\section{Tissue Analysis}

Pancreases were homogenized and extracted in acid-ethanol $(1.5 \% \mathrm{HCl}$ in $70 \% \mathrm{EtOH})$ for determination of insulin content. Protein contents of the extracts were estimated using the Bio-Rad DC Protein Assay (Bio-Rad Laboratories, CA). Insulin contents (Mercodia High Range Rat Insulin ELISA; Mercodia AB) were analyzed according to manufactures' instruction.

\section{Data and Statistical Analyses}

All data are presented as mean \pm S.E.M. The statistical analyses of group differences were conducted using one-way ANOVA followed by Tukey's post hoc test for multiple comparison or two-way ANOVA followed by Dunnet's test for multiple comparison. Statistical analyses of nonparametric data were conducted using Kruskal Wallis test followed by Dunn's post hoc test for multiple comparison. Normality of data distribution was determined by Shapiro-Wilk normality test. All analyses were performed using GraphPad Prism 8 software (San Diego, CA). A value of $P<0.05$ was considered statistically significant.

\section{Results}

Body Weight Loss, Reduction of Food Intake, and Improvement of Glucose Tolerance Are Mainly Mediated through the Amylin Receptor in High-Fat DietFed Rats. To address how the AMY-R and the CTR each contribute to the beneficial effects of KBP-088, high-fat diet-fed rats received KBP-088 therapy in comparison with the selective agonists $\mathrm{rAMY}$ and $\mathrm{rCT}$ or a combination of the two. KBP-088 (5 $\mu \mathrm{g} / \mathrm{kg}$ per day s.c.), rAMY (300 $\mu \mathrm{g} / \mathrm{kg}$ per day s.c), and the combination of rAMY and $\mathrm{rCT}(300+300 \mu \mathrm{g} / \mathrm{kg}$ per day s.c.) significantly reduced food intake in the initial phase of the study, whereas $\mathrm{rCT}(300 \mu \mathrm{g} / \mathrm{kg}$ per day s.c.) alone only slightly reduced food intake, and this was only the 1st day after study start. In addition, KBP-088 and rAMY resulted in a prolonged reduction of food intake (Fig. 2B). Chronic treatment with KBP-088, rAMY, and the combination of rAMY and $\mathrm{rCT}$ resulted in a $17 \%, 11 \%$, and $8 \%$ vehiclecorrected weight loss, respectively, whereas $\mathrm{rCT}$ alone had no effect on body weight in HFD-fed rats (Fig. 2, A and C). Interestingly, KBP-088 was superior in terms of body weight loss even though rAMY and KBP-088 equally reduced the accumulated food intake (Fig. 2D). In addition, KBP-088 and rAMY tended to reduce overall adiposity across different fat depots (Fig. 2, E-G), whereas KBP-088 showed a modest reduction of liver weight (Fig. $2 \mathrm{H}$ ); however, when adjusting for body weight, no difference was observed.

An OGTT performed at study end showed a trend toward improvement in oral glucose tolerance in response to KBP088, rAMY, and the combination of rAMY and rCT (Fig. 3, A and $\mathrm{C}$ ). Underscoring the mode of action, this improvement was achieved with significantly reduced plasma insulin levels compared with vehicle, with KBP-088 being superior (Fig. 3, B and D). Moreover, KBP-088 significantly reduced gastricemptying rate by $33 \%$ compared with vehicle, whereas rAMY and the combination of $\mathrm{rAMY}$ and $\mathrm{rCT}$ resulted in gastricemptying rates reduced by approximately $20 \%$ compared with vehicle. $\mathrm{rCT}$ alone had no effect on the gastric-emptying rate (Fig. 3E). All beneficial treatment effects observed in HFD-fed rats are consistent with known effects of amylin receptor agonism.

Both the Calcitonin and Amylin Receptors Are Important for Improvement of Hyperglycemia in Diabetic Rats. To elucidate how the AMY-R and CTR contribute to the effects of KBP-088 on blood glucose levels, KBP-088 was compared with the selective agonists rAMY and $\mathrm{rCT}$ or a combination of the two in diabetic ZDF rats. ZDF rats were left untreated until the age of 11 weeks, when hyperglycemia had developed, and fasting blood glucose levels had increased to an average of $11.3 \pm 5.7$ (S.D.) $\mathrm{mM}$. After development of hyperglycemia, treatment was initiated by insertion of infusion pumps containing saline (vehicle), KBP-088 (5 $\mu \mathrm{g} / \mathrm{kg}$ per day s.c.), $\mathrm{rAMY}(300 \mu \mathrm{g} / \mathrm{kg}$ per day s.c.), $\mathrm{rCT}(300 \mu \mathrm{g} / \mathrm{kg}$ per day s.c.) or a combination of rAMY and $\mathrm{rCT}(300+300 \mu \mathrm{g} / \mathrm{kg}$ per day s.c.). rAMY, the combination of rAMY and $\mathrm{rCT}$, and KBP-088 initially reduced the food intake and body weight, although they normalized to vehicle levels during the study. Only KBP088 treatment resulted in a minor body weight reduction at study end, even though the food intake was normalized (Fig. 4, A and B). In accordance with the body weights at study end, no marked differences in overall adiposity was observed (Table 1). All treatments resulted in an immediate reduction in fasting blood glucose levels (Fig. 4E) independent of the effect on food intake (Fig. 4C). rCT and rAMY were efficient in lowering fasting blood glucose levels to the same extent, whereas dual receptor activation by KBP-088 and the combination of $\mathrm{rAMY}$ and $\mathrm{rCT}$ were superior to activating either receptor alone (Fig. 4, E and F). The blood glucose-lowering effect induced by dual receptor activation was sustained throughout the study, whereas the effect of either $\mathrm{rCT}$ or $\mathrm{rAMY}$ was reduced toward the end of the treatment period (Fig. 4E). Furthermore, at study end all 
A

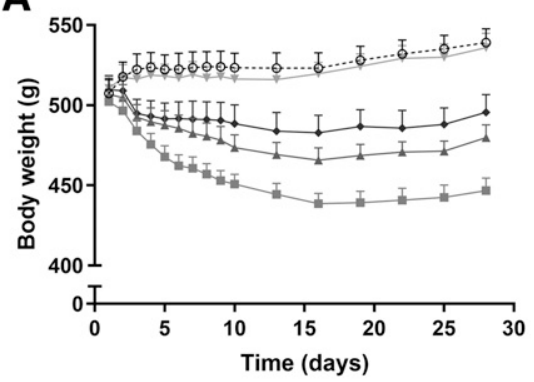

B

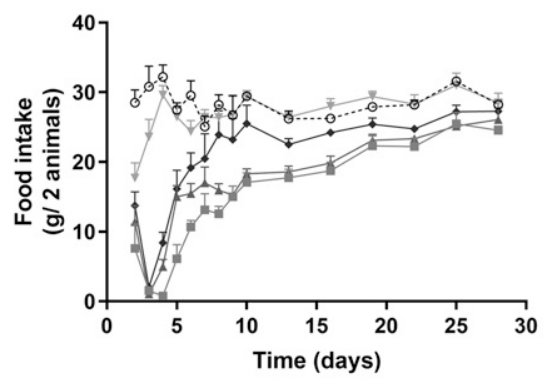

$-\odot$ Vehicle $\rightarrow \mathrm{KBP}-0885 \mu \mathrm{g} / \mathrm{kg} \rightarrow \mathrm{rAMY} 300 \mu \mathrm{g} / \mathrm{kg} \rightarrow \mathrm{rCT} 300 \mu \mathrm{gg} / \mathrm{kg} \rightarrow-\mathrm{rAMY}+\mathrm{rCT} 300 \mu \mathrm{g} / \mathrm{kg}$

C

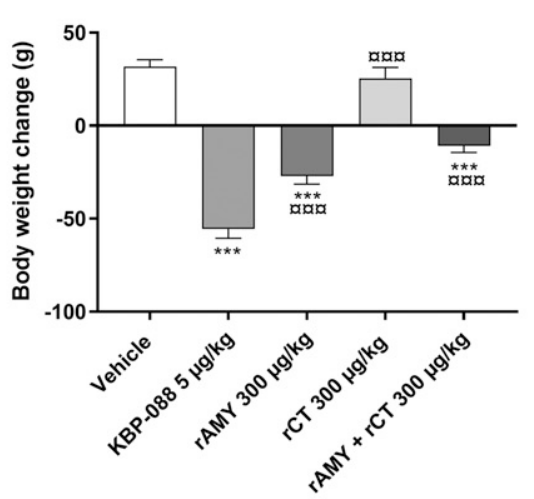

$E$

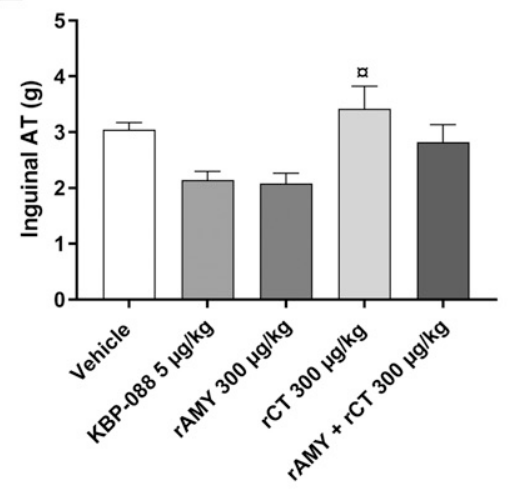

G

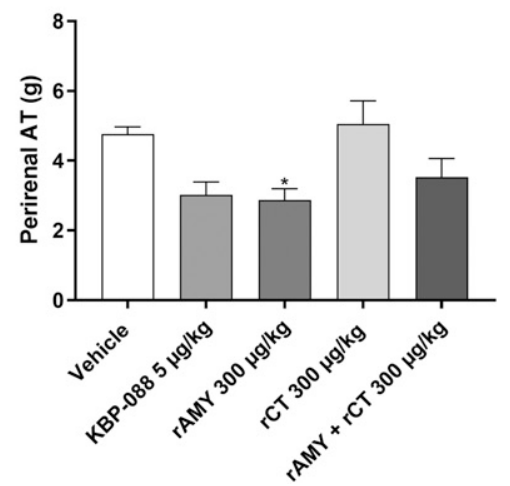

D

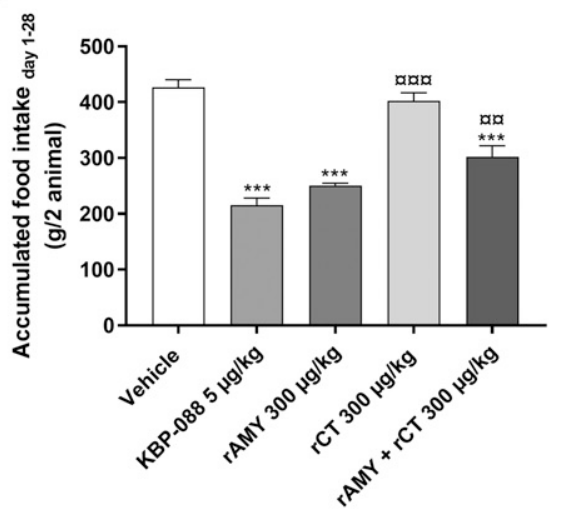

$\mathbf{F}$

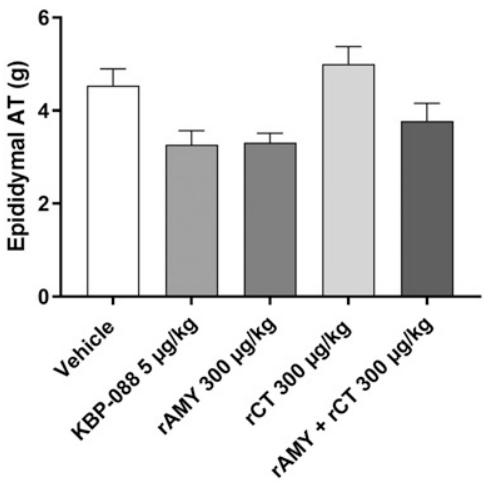

H

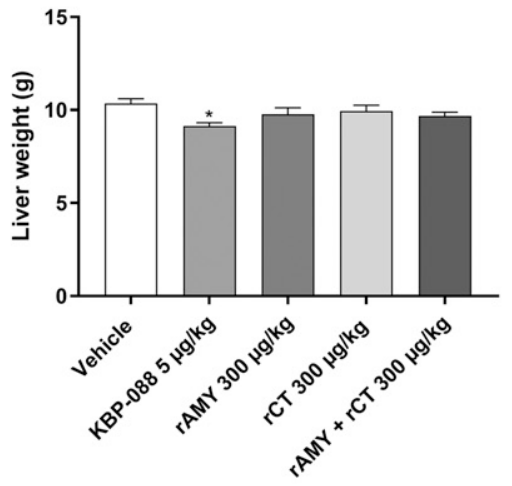

Fig. 2. Body weight (A) and food intake (B) of HFD-fed rats during the study. Body weight change (C) and accumulated food intake (D) at study end. Weight of inguinal (E), epididymal (F) and perirenal $(\mathrm{G})$ adipose tissue, and liver $(\mathrm{H})$ at study end. Food intake, adipose tissue weight (epididymal and inguinal), and liver weight data are analyzed by one-way ANOVA followed by Tukey's multiple comparisons test. Body weight and perirenal adipose tissue weight data are analyzed by Kruskal Wallis followed by Dunn's multiple comparisons test. $* P<0.05 ; * * * P<0.001$ compared with vehicle and $a P<0.05$ a. $P<0.01$; a.a $P<0.001$ compared with KBP-088, $n=8$ rats per treatment group. Data are shown as mean \pm S.E.M. AT, adipose tissue. 
A

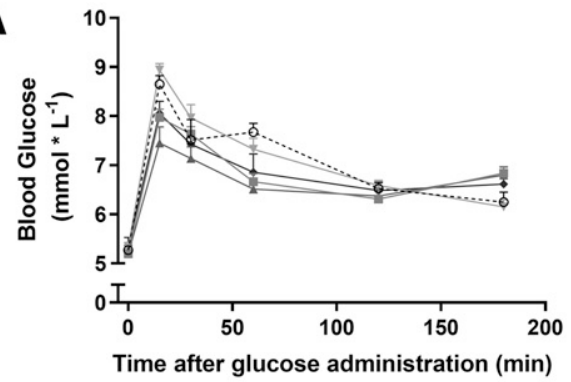

B

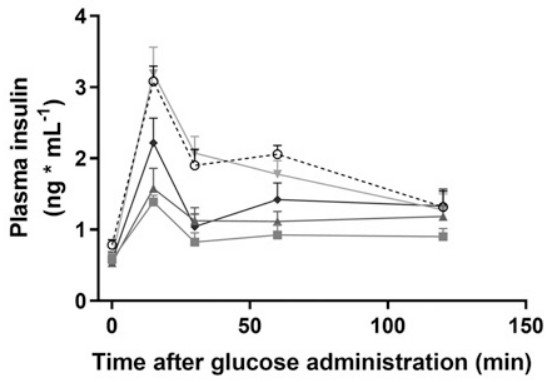

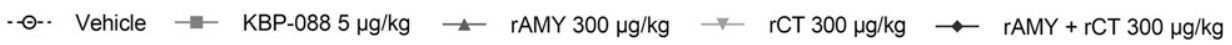

C

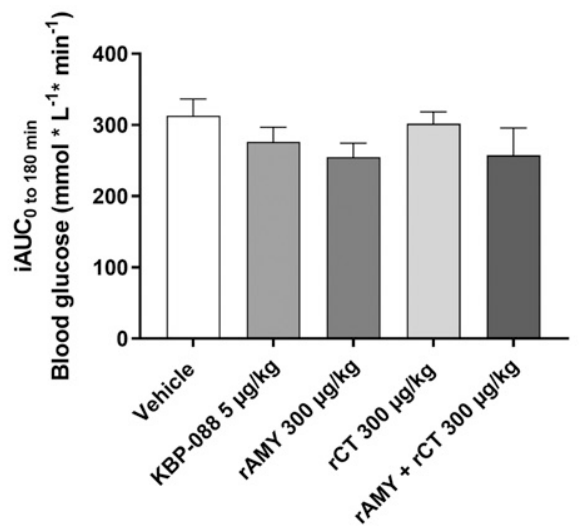

E

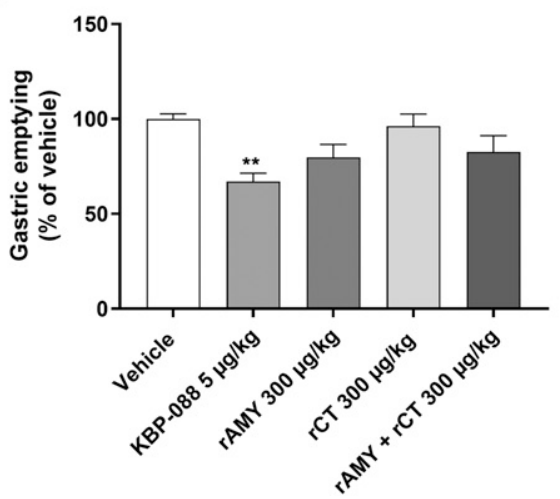

D

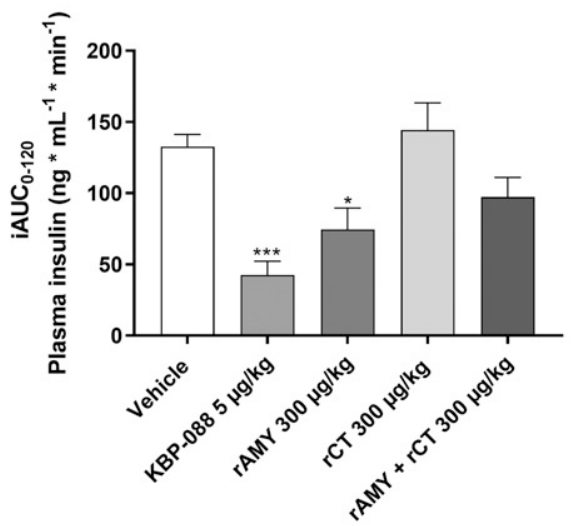

Fig. 3. Blood glucose (A) and plasma insulin (B) levels during the oral glucose tolerance test in HFD-fed rats. tAUC of blood glucose (C) and plasma insulin (D). Gastric emptying 30 minutes postadministration as percentage of vehicle (E). Insulin data are analyzed by one-way ANOVA followed by Tukey's multiple comparisons test, and gastric-emptying data are analyzed by Kruskal Wallis followed by Dunn's multiple comparisons test. $* P<0.05 ; * * P<0.01 ; * * * P<0.001$ compared with vehicle. $n=8$ rats per treatment group. Data are shown as mean \pm S.E.M. iAUC, incremental area under the curve. treatments tended to lower HbA1c levels compared with vehicle, although only KBP-088 significantly (Fig. 4D). These trends corresponded well with the fasting blood glucose levels.

Dual Receptor Activation through Chronic Therapy Improves Glucose Tolerance Superior to Activating Either Receptor Alone. During OGTT, all treatments led to improved glucose tolerance compared with vehicle, although only KBP-088 and the combination of rAMY and rCT significantly (Fig. 5, A and C). However, the differences in glucose levels during the OGTT were defined by the fasting blood glucose levels at test start (Fig. 5A). These differences in fasting levels are reflected in the tAUC, in which treatment with KBP-088 and the combination of rAMY and $\mathrm{rCT}$ led to a significant reduction in tAUC
(Fig. 5C) and are further confirmed because the incremental area under the curve shows no significant differences between treatments (Fig. 5E). The improved glucose tolerance was also reflected in the plasma insulin levels during OGTT, in which treatment with KBP-088 and the combination of $\mathrm{rAMY}$ and $\mathrm{rCT}$ tended to increase the plasma insulin levels compared with the other treatment groups (Fig. 5, B and D). Gastric-emptying rate was reduced by approximately $20 \%$ compared with vehicle by KBP-088, rAMY, and rCT, whereas the combination of rAMY and rCT significantly reduced gastric emptying by $30 \%$ compared with vehicle (Fig. $5 \mathrm{~F}$ ).

Dual Receptor Activation Is Important for Long-Term Improvement of Hyperglycemia. KBP-088 and the combination of rAMY and $\mathrm{rCT}$ significantly reduced fasting blood 
A

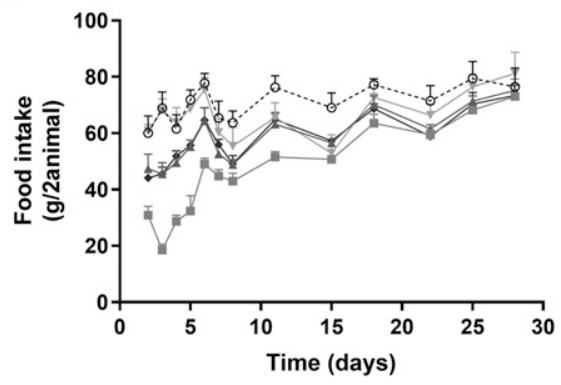

B

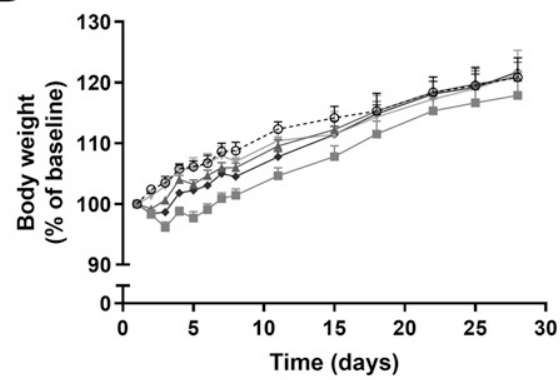

$-\odot \cdot$ Vehicle $\rightarrow$ KBP-088 $5 \mu \mathrm{g} / \mathrm{kg} \rightarrow \mathrm{rAMY} 300 \mu \mathrm{g} / \mathrm{kg} \rightarrow \mathrm{rCT} 300 \mu \mathrm{g} / \mathrm{kg} \rightarrow \mathrm{rAMY}+\mathrm{rCT} 300 \mu \mathrm{gg} / \mathrm{kg}$

C

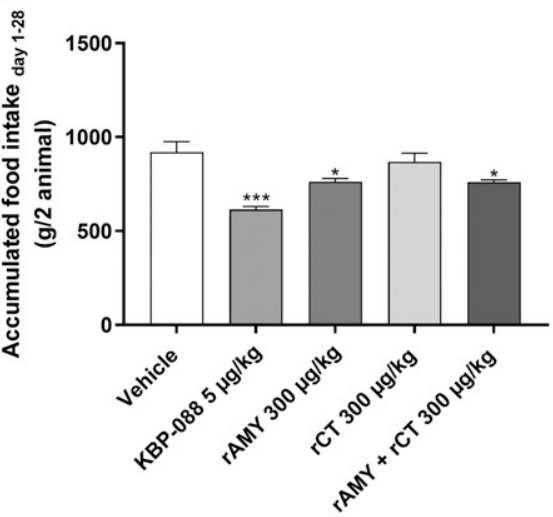

E

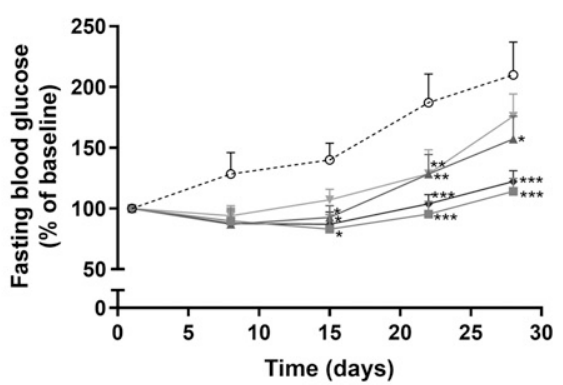

D
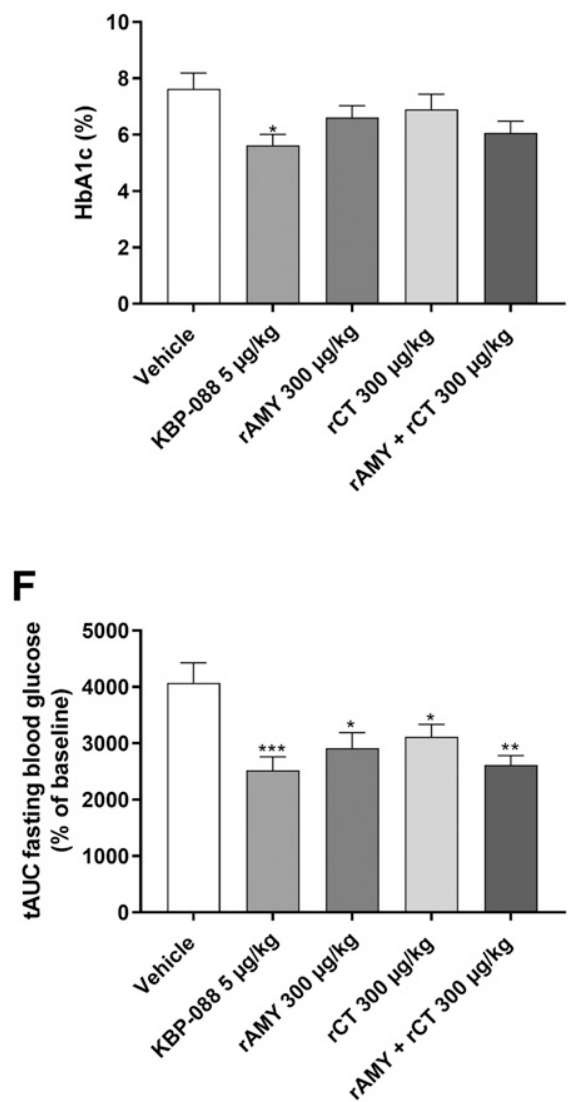

Fig. 4. Food intake of ZDF rats during the study (A). Body weight during the study shown as percentage of baseline (B). Accumulated food intake (C) and HbA1c levels (D) at study end. Fasting (6 hours) blood glucose levels during the study as percentage of fasting blood glucose levels at baseline (E). Calculated tAUC of fasting blood glucose levels (\% of baseline) (F). HbA1c levels and tAUC values are analyzed by one-way ANOVA followed by Dunnett's multiple comparison test and fasting blood glucose levels during the study are analyzed by two-way ANOVA followed by Dunnett's multiple comparison test. $* P<0.05 ; * * P<0.01$; *** $P<0.001$ compared with vehicle. $n=8$ rats per treatment group. Data are shown as mean \pm S.E.M glucose levels at study end, whereas rCT or rAMY alone only tended to reduce blood glucose levels at this time point (Fig. 6A). In addition, fasting insulin levels at study end were slightly increased by all treatments, with
KBP-088 having the most pronounced effect (Fig. 6B). This was reflected in the pancreatic insulin contents (Fig. 6C), suggesting that dual receptor activation by KBP-088 improved regulation of blood glucose levels

TABLE 1

Adiposity in the ZDF rats at study end.

Weights of inguinal, epididymal and perirenal adipose tissue (AT) at study end. Data are shown as mean \pm S.E.M.

\begin{tabular}{lccc}
\hline & Inguinal AT $(\mathrm{g})$ & Epididymal AT $(\mathrm{g})$ & Perirenal AT $(\mathrm{g})$ \\
\hline Vehicle $(n=8)$ & $4.5 \pm 0.3$ & $3.9 \pm 0.3$ & $5.1 \pm 0.3$ \\
KBP-088 $5 \mu \mathrm{g} / \mathrm{kg}(n=8)$ & $4.3 \pm 0.3$ & $3.6 \pm 0.1$ & $5.0 \pm 0.2$ \\
rAMY 300 $\mu \mathrm{g} / \mathrm{kg}(n=8)$ & $4.6 \pm 0.3$ & $4.1 \pm 0.2$ & $5.2 \pm 0.2$ \\
rCT 300 $\mu \mathrm{g} / \mathrm{kg}(n=8)$ & $4.6 \pm 0.4$ & $4.0 \pm 0.2$ & $5.1 \pm 0.3$ \\
rAMY $+\mathrm{rCT} 300 \mu \mathrm{g} / \mathrm{kg}(n=8)$ & $4.8 \pm 0.2$ & $4.1 \pm 0.2$ & $5.6 \pm 0.3$ \\
\hline
\end{tabular}


A

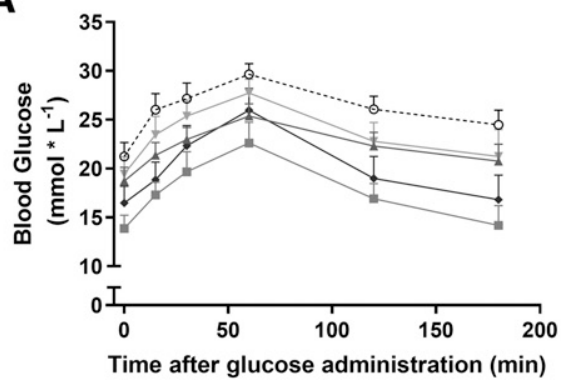

B

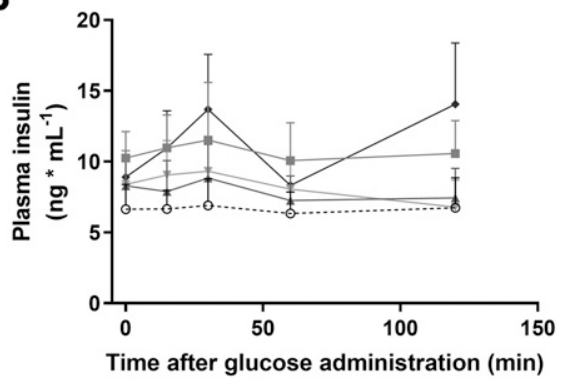

$-\odot$-. Vehicle $\rightarrow \mathrm{MBP}-0885 \mu \mathrm{g} / \mathrm{kg} \rightarrow \mathrm{rAMY} 300 \mu \mathrm{g} / \mathrm{kg} \rightarrow \mathrm{rCT} 300 \mu \mathrm{g} / \mathrm{kg} \quad \longrightarrow \quad \mathrm{rAMY}+\mathrm{rCT} 300 \mu \mathrm{gg} / \mathrm{kg}$

C

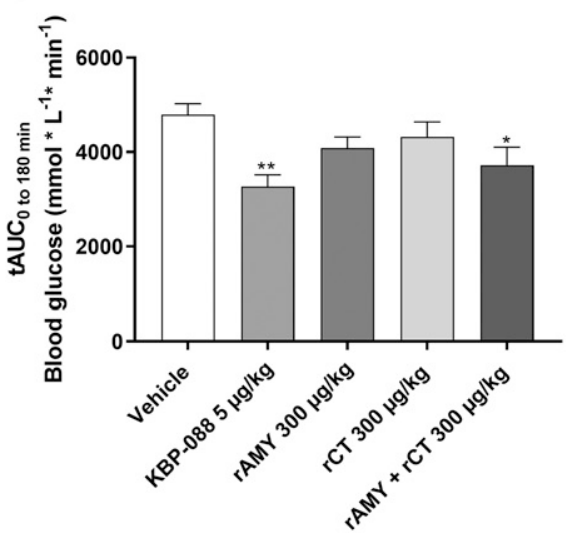

E

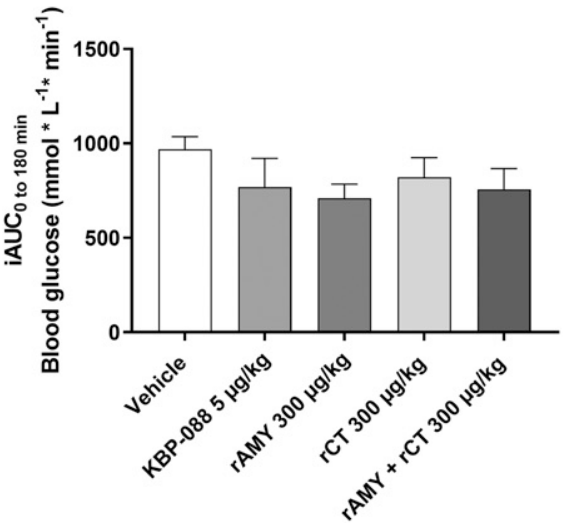

D

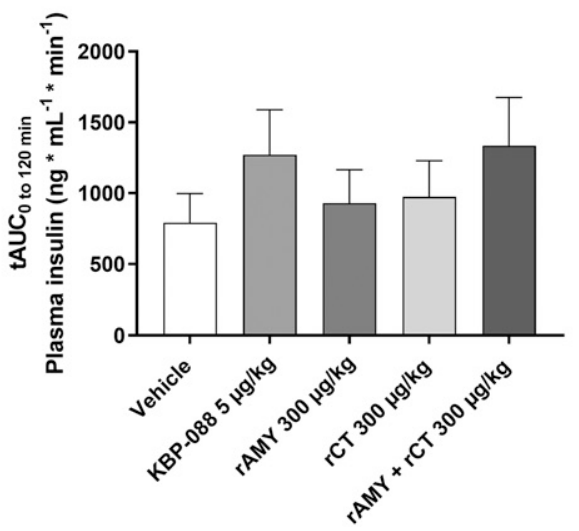

$\mathbf{F}$

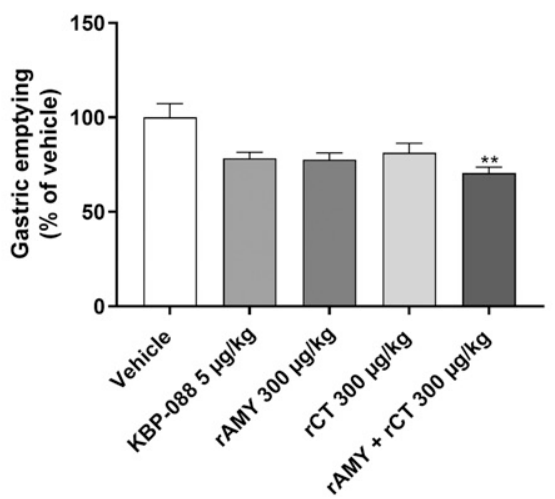

Fig. 5. Blood glucose (A) and plasma insulin (B) levels during the oral glucose tolerance test in $\mathrm{ZDF}$ rats. tAUC of blood glucose $(\mathrm{C})$ and plasma insulin (D). Incremental area under the curve (iAUC) of blood glucose (E). Gastric emptying 30 minutes postadministration as percentage of vehicle $(\mathrm{F})$. Insulin data are analyzed by one-way ANOVA followed by Tukey's multiple comparisons test and gastric-emptying data are analyzed by Kruskal Wallis followed by Dunn's multiple comparisons test. $* P<0.05 ; * * P<$ 0.01 compared with vehicle. $n=8$ rats per treatment group. Data are shown as mean \pm S.E.M. by increased pancreatic insulin content as well as secretion.

\section{Discussion}

We demonstrate that the calcitonin-mediated activation of CTR is a critical component in fasting blood glucose regulation by dual amylin and calcitonin receptor agonists in a diabetic rat model. Importantly, these data show that the overall metabolic effects of the DACRAs involve not only potent activation of the AMY-R but also of the CTR to elicit glucose control.

To understand these data, similarities between AMY-R and CTRs must be kept in mind. The CTR and the AMY-R are highly similar, with the primary difference being the association of a RAMP to the AMY-R and not the CTR (Armour et al., 1999; Christopoulos et al., 1999; Muff et al., 1999). These receptors are highly selective in their ligand binding, with amylin binding the AMY-R and calcitonin binding the CTR (Christopoulos et al., 1999; Muff et al., 1999; Hay et al., 2015). However, several studies showing additional potential of dual agonists on metabolic effects have been published (Andreassen et al., 2014a; Gydesen et al., 2016, 2017b; Hjuler et al., 2016, 2017; Larsen et al., 2019), and therefore understanding how these additional effects arise require a deconstruction of the involvement of the individual receptors. To shed light on the receptor involvement, we compensated for differences in activity between the selective and the dual agonists by 

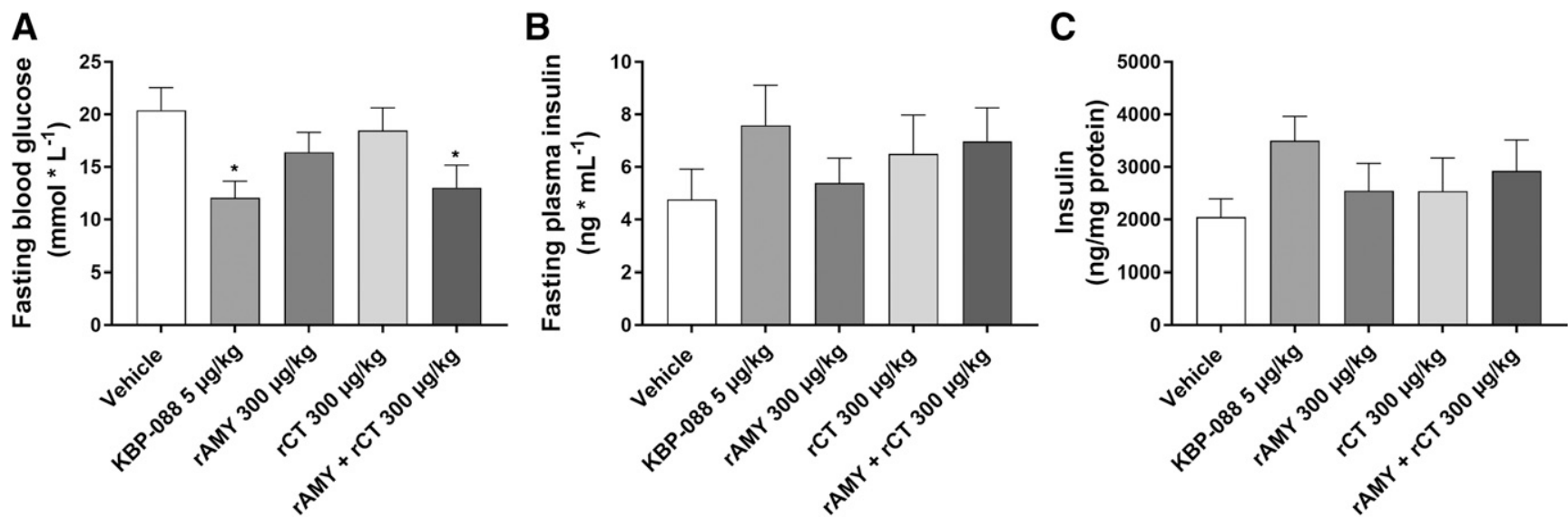

Fig. 6. Fasting (6 hours) blood glucose (A) and plasma insulin (B) in ZDF rats at study end. Pancreatic insulin content calculated as nanogram insulin per milligram protein $(\mathrm{C})$. Data are analyzed by one-way ANOVA followed by Dunnett's multiple comparison test. $* P<0.05$ compared with vehicle. $n=8$ rats per treatment group. Data are shown as mean \pm S.E.M.

continuously delivering peptides through osmotic pumps and by use of high doses of the selective agonists.

We found that rCT alone possessed a glucoregulatory effect in the diabetic rat, whereas it neither in the diabetic model nor in the obese model possessed the ability to regulate food intake and body weight, which was consistent with these being classic AMY-R-mediated effects (Roth et al., 2006; Mack et al., 2007; Lutz, 2012; Hay et al., 2015). Importantly, when combining rCT and rAMY, the full dual-agonist response on fasting blood glucose was obtained, clearly illustrating the added benefit of CTR agonism for the treatment of type 2 diabetes. Our data also show that the effects of the tested peptides are dependent on the disease stage. In HFD-fed animals, the main effect of KBP-088 was mediated through the AMY-R, resulting in body weight loss, reduction in food intake, and improved glucose tolerance in animals treated with KBP-088, rAMY, or the combination of rAMY and rCT. This improved glucose tolerance was obtained with significantly reduced insulin levels, which corresponds with previous studies showing that both DACRAs (Andreassen et al., 2014a; Hjuler et al., 2015, 2016; Gydesen et al., 2016, 2017a) and infusion of amylin (Roth et al., 2006; Trevaskis et al., 2010; Larsen et al., 2019) reduce plasma insulin in rat models of obesity. In diabetic ZDF rats, on the other hand, CTR activation was found to be essential for the beneficial effects of KBP-088 by lowering fasting glycemia, HbA1c levels, and gastric-emptying rate and improving glucose tolerance.

The ability of rAMY but not $\mathrm{rCT}$ to reduce food intake in both HFD-fed rats and ZDF rats suggests that the anorectic effect of DACRAs is mainly mediated through activation of the AMY-R. Furthermore, the reduction in food intake in HFD-fed rats corresponds to the reduction in body weight induced by both rAMY, KBP-088, and the combination of rAMY and rCT. This is consistent with other studies showing that chronic administration of amylin and amylin analogs reduces body weight and food intake in diet-induced obese rodents (Mack et al., 2003; Roth et al., 2006) and obese subjects (Aronne et al., 2007; Smith et al., 2008). Interestingly, KBP-088 was superior in terms of inducing a sustained weight loss in both rat models despite having an accumulated food intake similar to rAMYtreated rats. This corresponds well with previous studies showing that infusion of the dual agonists davalintide (Mack et al., 2011) and KBP-088 (Larsen et al., 2019) is superior to amylin in reducing body weight in obese rats, albeit the mechanism behind this superiority is unclear because it does not appear to entail the CTR. The weight loss observed using the infusion pumps was very consistent with previous reports (Larsen et al., 2019) and has been reported to be through a combination of effects on appetite regulation and an increase in energy expenditure (Wielinga et al., 2010; FernandesSantos et al., 2013; Park et al., 2015; Hjuler et al., 2016). We speculate that the superiority of KBP-088 in terms of body weight loss may be caused by pharmacological challenges observed with amylin because increasing doses of amylin does not improve the efficacy (Larsen et al., 2019). The mechanism of action underlying the weight loss is known to include appetite regulation, an effect mediated by amylin receptors expressed in the area postrema (Hay et al., 2015); however, there are also studies indicating direct effects on the adipocytes of amylin, although the effects appear to be related to insulin sensitivity more so than weight loss (Moon et al., 2011; Miegueu et al., 2013). Interestingly, the calcitonin receptor does not appear to be involved in this pharmacological response because calcitonin receptor knockout mice have no overt adipose tissue phenotype (Bartelt et al., 2017).

To the best of our knowledge, the effect of rCT on fasting blood glucose and $\mathrm{HbA} 1 \mathrm{c}$ is an effect not previously reported. An old study found CT infusion to reduce blood glucose levels in patients with diabetes, supporting our observations (Starke et al., 1981). However, Starke et al. (1981) used salmon calcitonin, which is now known to be a DACRA and hence also activates AMY-R (Christopoulos et al., 1999; Young, 2005). In line with this, it has been found that CTR knockout mice have impaired glucose tolerance (Bartelt et al., 2017). Albeit, a CTR knockout will also affect the AMY-Rs because the AMY-R is a CTR with a RAMP (Armour et al., 1999; Christopoulos et al., 1999; Muff et al., 1999). Hence it cannot be excluded that the observed effects are related to the AMY$R$. In contrast, they found a deletion of the CT gene to improve glucose tolerance and protect from diet-induced obesity in mice (Bartelt et al., 2017). Furthermore, another recent paper found a CT gene deletion to prevent obesity and hyperglycemia in aged obese mice (Nakamura et al., 2018). Even though these papers suggest that CT has a negative effect on glucose 
metabolism, they confirm an association between CT and glucose metabolism. In addition, the studies were performed in knockout mice, making it difficult to compare with the present data, which is focused on the pharmacological responses of CT. Furthermore, knockout of RAMPs cannot be used to study AMY-R-related effects because RAMPs can associate with a number of other receptors, including CGRP-R (Hay and Pioszak, 2016; Hay et al., 2016). Hence several receptors will be affected by an RAMP knockout.

Our data suggest that the beneficial effect of KBP-088 and other DACRAs on fasting blood glucose and HbA1c levels (Feigh et al., 2014; Gydesen et al., 2017b; Hjuler et al., 2017) is mediated through activation of both the CTR and the AMY-R, an effect not driven by body weight loss, and thereby appears to be independent of reductions in adipocyte size and numbers, which are known to be essential for the weight-lowering effects of both DACRAs and amylin (Gydesen et al., 2017b; Hjuler et al., 2017; Duffy et al., 2018). With respect to the postprandial effects on blood glucose, one could speculate that the effect of amylin on this parameter is mainly driven by its ability to lower blood glucose by suppressing inappropriate glucagon secretion and slowing gastric emptying as well as its anorectic effect (Hay et al., 2015; Hay, 2017). In ZDF rats, rCT reduced gastric-emptying rate similar to KBP-088 and rAMY, which might contribute to the positive effect on blood glucose levels, albeit mainly the postprandial levels. The beneficial effect on blood glucose might also indicate a preserved betacell mass as shown in previous DACRA studies (Andreassen et al., 2014a; Hjuler et al., 2017). This is confirmed by increased pancreatic insulin content in rats treated with KBP-088.

With these data in mind, questions about the receptor construction in the different target tissues arise, and future studies will address whether one or both target receptors are present in the tissues of interest for glucose deposition (i.e., muscles, fat, and liver). An intriguing finding is that amylin and calcitonin therapy alone appear to lose glucose control over time, whereas the combination maintains the ability. These data potentially indicate that dual activation evokes a different route of receptor regulation than selective activation, although this has not been studied in further detail.

In conclusion, the calcitonin receptor is essential for blood glucose regulation in a diabetic rat model receiving DACRA therapy, whereas the amylin receptor affects both blood glucose levels and food intake. However, dual activation of amylin and calcitonin receptors by KBP-088 or the combination of $\mathrm{rAMY}$ and $\mathrm{rCT}$ is superior to activating either receptor alone in terms of reducing body weight and improving HbA1c levels and glucose control. Thus, the DACRA KBP-088 offers a promising mode of action as a therapy for metabolic conditions.

\section{Acknowledgments}

We would like to acknowledge funding grant from the Danish Research Foundation (Den Danske Forskningsfond).

\section{Authorship Contributions}

Participated in research design: Larsen, Karsdal, Henriksen. Conducted experiments: Larsen.

Performed data analysis: Larsen, Sonne, Andreassen.

Wrote or contributed to writing the manuscript: Larsen, Henriksen.

\section{References}

Andreassen KV, Feigh M, Hjuler ST, Gydesen S, Henriksen JE, Beck-Nielsen H, Christiansen C, Karsdal MA, and Henriksen K (2014a) A novel oral dual amylin and calcitonin receptor agonist (KBP-042) exerts antiobesity and antidiabetic effects in rats. Am J Physiol Endocrinol Metab 307:E24-E33.

Andreassen KV, Hjuler ST, Furness SG, Sexton PM, Christopoulos A, Nosjean O, Karsdal MA, and Henriksen K (2014b) Prolonged calcitonin receptor signaling by salmon, but not human calcitonin, reveals ligand bias. PLoS One 9:e92042.

Armour SL, Foord S, Kenakin T, and Chen WJ (1999) Pharmacological characterization of receptor-activity-modifying proteins (RAMPs) and the human calcitonin receptor. J Pharmacol Toxicol Methods 42:217-224.

Aronne L, Fujioka K, Aroda V, Chen K, Halseth A, Kesty NC, Burns C, Lush CW, and Weyer C (2007) Progressive reduction in body weight after treatment with the amylin analog pramlintide in obese subjects: a phase 2, randomized, placebocontrolled, dose-escalation study. J Clin Endocrinol Metab 92:2977-2983.

Bartelt A, Jeschke A, Müller B, Gaziano I, Morales M, Yorgan T, Heckt T, Heine M, Gagel RF, Emeson RB, et al. (2017) Differential effects of Calca-derived peptides in male mice with diet-induced obesity. PLoS One 12:e0180547.

Christopoulos G, Perry KJ, Morfis M, Tilakaratne N, Gao Y, Fraser NJ, Main MJ, Foord SM, and Sexton PM (1999) Multiple amylin receptors arise from receptor activity-modifying protein interaction with the calcitonin receptor gene product. Mol Pharmacol 56:235-242.

Duffy S, Lutz TA, and Boyle CN (2018) Rodent models of leptin receptor deficiency are less sensitive to amylin. Am J Physiol Regul Integr Comp Physiol 315: R856-R865.

Dunican KC, Adams NM, and Desilets AR (2010) The role of pramlintide for weight loss. Ann Pharmacother 44:538-545.

Feigh M, Hjuler ST, Andreassen KV, Gydesen S, Ottosen I, Henriksen JE, BeckNielsen H, Christiansen C, Karsdal MA, and Henriksen K (2014) Oral salmon calcitonin enhances insulin action and glucose metabolism in diet-induced obese streptozotocin-diabetic rats. Eur J Pharmacol 737:91-96.

Fernandes-Santos C, Zhang Z, Morgan DA, Guo DF, Russo AF, and Rahmouni K (2013) Amylin acts in the central nervous system to increase sympathetic nerve activity. Endocrinology 154:2481-2488.

Findlay DM and Sexton PM (2004) Calcitonin. Growth Factors 22:217-224.

Gydesen S, Andreassen KV, Hjuler ST, Christensen JM, Karsdal MA, and Henriksen K (2016) KBP-088, a novel DACRA with prolonged receptor activation, is superior to davalintide in terms of efficacy on body weight. Am J Physiol Endocrinol Metab 310:E821-E287 DOI: 10.1152/ajpendo.00514.2015.

Gydesen S, Andreassen KV, Hjuler ST, Hellgren LI, Karsdal MA, and Henriksen K (2017a) Optimization of tolerability and efficacy of the novel dual amylin and calcitonin receptor agonist KBP-089 through dose escalation and combination with a GLP-1 analog. Am J Physiol Endocrinol Metab 313:E598-E607 DOI: 10.1152/ ajpendo.00419.2016.

Gydesen S, Hjuler ST, Freving Z, Andreassen KV, Sonne N, Hellgren LI, Karsdal MA, and Henriksen K (2017b) A novel dual amylin and calcitonin receptor agonist, KBP-089, induces weight loss through a reduction in fat, but not lean mass, while improving food preference. Br J Pharmacol 174:591-602 DOI: 10.1111/bph.13723. Hay DL (2017) Amylin. Headache 57 (Suppl 2):89-96.

Hay DL, Chen S, Lutz TA, Parkes DG, and Roth JD (2015) Amylin: pharmacology, physiology, and clinical potential. Pharmacol Rev 67:564-600.

Hay DL and Pioszak AA (2016) Receptor activity-modifying proteins (RAMPs): new insights and roles. Annu Rev Pharmacol Toxicol 56:469-487.

Hay DL, Walker CS, Gingell JJ, Ladds G, Reynolds CA, and Poyner DR (2016) Receptor activity-modifying proteins; multifunctional $\mathrm{G}$ protein-coupled receptor accessory proteins. Biochem Soc Trans 44:568-573.

Henriksen K, Byrjalsen I, Andersen JR, Bihlet AR, Russo LA, Alexandersen P, Valter I, Qvist P, Lau E, Riis BJ, et al.; SMC021 investigators (2016) A randomized, double-blind, multicenter, placebo-controlled study to evaluate the efficacy and safety of oral salmon calcitonin in the treatment of osteoporosis in postmenopausa women taking calcium and vitamin D. Bone 91:122-129.

Herrmann K, Shan K, Brunell SC, and Chen S (2014) Effects of pramlintide in patients with type 2 diabetes mellitus: an analysis using daily insulin dose tertiles. Endocr Pract 20:1070-1075.

Hjuler ST, Andreassen KV, Gydesen S, Karsdal MA, and Henriksen K (2015) KBP042 improves bodyweight and glucose homeostasis with indices of increased insulin sensitivity irrespective of route of administration. Eur J Pharmacol 762:229-238.

Hjuler ST, Gydesen S, Andreassen KV, Karsdal MA, and Henriksen K (2017) The dual amylin- and calcitonin-receptor agonist KBP-042 works as adjunct to metformin on fasting hyperglycemia and $\mathrm{HbA1c}$ in a rat model of type 2 diabetes. $J$ Pharmacol Exp Ther 362:24-30 DOI: 10.1124/jpet.117.241281.

Hjuler ST, Gydesen S, Andreassen KV, Pedersen SL, Hellgren LI, Karsdal MA and Henriksen K (2016) The dual amylin- and calcitonin-receptor agonist KBP-042 increases insulin sensitivity and induces weight loss in rats with obesity. Obesity (Silver Spring) 24:1712-1722.

Hollander PA, Levy P, Fineman MS, Maggs DG, Shen LZ, Strobel SA, Weyer C, and Kolterman OG (2003) Pramlintide as an adjunct to insulin therapy improves long-term glycemic and weight control in patients with type 2 diabetes. Diabetes Care 26:784-790.

Inzerillo AM, Zaidi M, and Huang CL-H (2004) Calcitonin: physiological actions and clinical applications. J Pediatr Endocrinol Metab 17:931-940.

King AJF (2012) The use of animal models in diabetes research. Br J Pharmacol 166: 877-894.

Larsen AT, Sonne N, Andreassen KV, Gehring K, Karsdal MA, and Henriksen K (2019) The dual amylin and calcitonin receptor agonist KBP-088 induces weight loss and improves insulin sensitivity superior to chronic amylin therapy. $J$ Pharmacol Exp Ther 370:35-43.

Lutz TA (2012) Effects of amylin on eating and adiposity, Handb Exp Pharmacol 209, pp 231-250, (OSpringer-Verlag. 
Mack C, Hoyt J, Moore C, Jodka C, and Sams-Dodd F (2003) Sustained reduction in food intake and body weight in high-fat-fed rats during 28-day amylin infusion (Abstract). Diabetes 52:A389.

Mack C, Wilson J, Athanacio J, Reynolds J, Laugero K, Guss S, Vu C, Roth J, and Parkes D (2007) Pharmacological actions of the peptide hormone amylin in the long-term regulation of food intake, food preference, and body weight. Am J Physiol Regul Integr Comp Physiol 293:R1855-R1863.

Mack CM, Smith PA, Athanacio JR, Xu K, Wilson JK, Reynolds JM, Jodka CM, Lu MGW, and Parkes DG (2011) Glucoregulatory effects and prolonged duration of action of davalintide: a novel amylinomimetic peptide. Diabetes Obes Metab 13: 1105-1113.

Miegueu P, St-Pierre DH, Munkonda MN, Lapointe M, and Cianflone K (2013) Amylin stimulates fatty acid esterification in 3T3-L1 adipocytes. Mol Cell Endocrinol 366:99-107.

Moon HS, Chamberland JP, Diakopoulos KN, Fiorenza CG, Ziemke F, Schneider B, and Mantzoros CS (2011) Leptin and amylin act in an additive manner to activate overlapping signaling pathways in peripheral tissues: in vitro and ex vivo studies in humans. Diabetes Care 34:132-138.

Muff R, Bühlmann N, Fischer JA, and Born W (1999) An amylin receptor is revealed following co-transfection of a calcitonin receptor with receptor activity modifying proteins-1 or -3. Endocrinology 140:2924-2927.

Nakamura M, Nomura S, Yamakawa T, Kono R, Maeno A, Ozaki T, Ito A, Uzawa T, Utsunomiya H, and Kakudo K (2018) Endogenous calcitonin regulates lipid and glucose metabolism in diet-induced obesity mice. Sci Rep 8:17001.

Park H, Cho S, Janat-Amsbury MM, and Bae YH (2015) Enhanced thermogenic program by non-viral delivery of combinatory browning genes to treat diet-induced obesity in mice. Biomaterials 73:32-41.

Pick A, Clark J, Kubstrup C, Levisetti M, Pugh W, Bonner-Weir S, and Polonsky KS (1998) Role of apoptosis in failure of beta-cell mass compensation for insulin resistance and beta-cell defects in the male Zucker diabetic fatty rat. Diabetes 47: 358-364.

Ratner RE, Dickey R, Fineman M, Maggs DG, Shen L, Strobel SA, Weyer C, and Kolterman OG (2004) Amylin replacement with pramlintide as an adjunct to insulin therapy improves long-term glycaemic and weight control in Type 1 diabetes mellitus: a 1-year, randomized controlled trial. Diabet Med 21: 1204-1212.

Riddle M, Frias J, Zhang B, Maier H, Brown C, Lutz K, and Kolterman O (2007) Pramlintide improved glycemic control and reduced weight in patients with type 2 diabetes using basal insulin. Diabetes Care 30:2794-2799.

Roth JD, Hughes H, Kendall E, Baron AD, and Anderson CM (2006) Antiobesity effects of the $\beta$-cell hormone amylin in diet-induced obese rats: effects on food intake, body weight, composition, energy expenditure, and gene expression. Endocrinology 147:5855-5864.
Ryan G, Briscoe TA, and Jobe L (2008) Review of pramlintide as adjunctive therapy in treatment of type 1 and type 2 diabetes. Drug Des Devel Ther 2:203-214.

Shibata T, Takeuchi S, Yokota S, Kakimoto K, Yonemori F, and Wakitani K (2000) Effects of peroxisome proliferator-activated receptor- $\alpha$ and $-\gamma$ agonist, JTT-501, on diabetic complications in Zucker diabetic fatty rats. Br J Pharmacol 130:495-504

Singh-Franco D, Perez A, and Harrington C (2011) The effect of pramlintide acetate on glycemic control and weight in patients with type 2 diabetes mellitus and in obese patients without diabetes: a systematic review and meta-analysis. Diabetes Obes Metab 13:169-180.

Smith SR, Aronne LJ, Burns CM, Kesty NC, Halseth AE, and Weyer C (2008) Sustained weight loss following 12-month pramlintide treatment as an adjunct to lifestyle intervention in obesity. Diabetes Care 31:1816-1823.

Starke A, Keck E, Berger M, and Zimmermann H (1981) Effects of calcium and calcitonin on circulating levels of glucagon and glucose in diabetes mellitus. Diabetologia 20:547-552

Tankó LB, Bagger YZ, Alexandersen P, Devogelaer JP, Reginster JY, Chick R, Olson M, Benmammar H, Mindeholm L, Azria M, et al. (2004) Safety and efficacy of a novel salmon calcitonin ( $\mathrm{SCT}$ ) technology-based oral formulation in healthy postmenopausal women: acute and 3-month effects on biomarkers of bone turnover. J Bone Miner Res 19:1531-1538.

Topp BG, Atkinson LL, and Finegood DT (2007) Dynamics of insulin sensitivity, -cell function, and -cell mass during the development of diabetes in fa/fa rats. Am $J$ Physiol Endocrinol Metab 293:E1730-E1735.

Traina AN and Kane MP (2011) Primer on pramlintide, an amylin analog. Diabetes Educ 37:426-431.

Trevaskis JL, Turek VF, Wittmer C, Griffin PS, Wilson JK, Reynolds JM, Zhao Y, Mack CM, Parkes DG, and Roth JD (2010) Enhanced amylin-mediated body weight loss in estradiol-deficient diet-induced obese rats. Endocrinology 151:5657-5668.

Weyer C, Maggs DG, Young AA, and Kolterman OG (2001) Amylin replacement with pramlintide as an adjunct to insulin therapy in type 1 and type 2 diabetes mellitus: a physiological approach toward improved metabolic control. Curr Pharm Des 7: 1353-1373.

Wielinga PY, Löwenstein C, Muff S, Munz M, Woods SC, and Lutz TA (2010) Central amylin acts as an adiposity signal to control body weight and energy expenditure. Physiol Behav 101:45-52

Young A (2005) Receptor pharmacology. Adv Pharmacol 52:47-65.

Younk LM, Mikeladze M, and Davis SN (2011) Pramlintide and the treatment of diabetes: a review of the data since its introduction. Expert Opin Pharmacother 12: 1439-1451.

Address correspondence to: Anna Thors $\emptyset$ Larsen, Nordic Bioscience, Herlev Hovedgade 207, 2730 Herlev, Denmark. E-mail: atl@nordicbio.com 